\title{
Analysis of ground deformation based on GPS in Sanshandao gold mine, China
}

\author{
Fengshan Ma ${ }^{1,2}$, *Hongyu Gu${ }^{1,2,3}$, Jie Guo ${ }^{1,2}$, and Rong Lu ${ }^{1,2}$ \\ ${ }^{1}$ Key Laboratory of Shale Gas and Geoengineering, Institute of Geology and Geophysics, Chinese Academy of Sciences, \\ Beijing, China \\ ${ }^{2}$ Institutions of Earth Science, Chinese Academy of Sciences, Beijing, China \\ ${ }^{3}$ University of Chinese Academy of Sciences \\ *Corresponding author: xy0909040129@126.com
}

\begin{abstract}
Sanshandao Gold Mine is the first and largest mine operating below sea level in China. Mining has been practiced in this region for at least 25 years. In recent years, buildings above the mining area have been extensively damaged. GPS (with 315 monitoring points) was used to monitor the ground deformation since 2009. Ground deformation induced by mining is much more complex in metal mine than that in coal mines due to the well-developed joints, high tectonic stress and several intersecting faults. All of the factors are analyzed in this study. The results show that discontinuous deformation has occurred on the surface because of the sliding to F3 (name of fault), and there are two motion patterns of F3 during the mining process. Additionally, joints in rock masses with steep dip angles contribute to the vertical displacement and joints with shallow dip angles contribute to the horizontal displacement. Meanwhile, high tectonic stress dramatically enlarges the scale of ground deformation, especially with respect to the horizontal displacement. This deformation results in a striped formation of compressed and stretched regions. Additionally, high-risk and potential risk areas are identified in this study. Finally, the successive data measured since 2009 can contribute to a deeper understanding of ground deformation in metal mine.
\end{abstract}

Keywords: Ground deformation, GPS, High tectonic stress, Fault, Discontinuous deformation, Risk area

Paper Received: 29 Jan 2018

Paper Accepted: 10 March 2018

\section{INTRODUCTION}

Mining activities have an effect on the environment. Many mining practices have frequently have caused serious disasters, such as damage to buildings, flooding and the loss of life (Loupasakis et al., 2014; Donnelly, 2006; Stecchi et al., 2012). The impact of mining is a complex spatial-temporal process depending on many factors, such as the type of mining, the size of the operation and the underground geological structures. Mining disturbs rock mass alters the topography and adversely affects the hydrogeological conditions. One of the most important effects on the environment of mining is ground deformation, which may occur over a wide area with continuous or discontinuous deformation. Many theories, including random medium theory (Guo et al., 2011) and empirical equations (Sheorey et al., 2000) have been used to predict the ground deformation induced by mining. Thus, these methods are applicable only in the coal mines, where ground deformation is mainly induced by gravity. The ground deformation of metal mines, especially gold mines with their own particular conditions, cannot be calculated or predicted by previous theories. Thus, regular monitor should be an effective method for developing deeper understanding of the process of ground deformation and for identifying the areas at high risk.

GPS and InSAR are effective and widely used methods for monitoring ground deformation. Can et al. (2013) used GPS data for 2009 and 2010 to analyze the ground deformation. Akçin et al. (2006) compared the deformations data from GPS and InSAR and found the coherence to be 0.8. Muntean et al. (2016) used GPS to study the land subsidence in the Petrosani (Romania) coal mining area. However, these studies mainly focused on coal mines, and only a few studies have investigated metal mines. Fengshan et al. (2015) used GPS to monitor the ground deformation in the nickel mine of Gansu Province, China since 1991.

The present study was carried out in the Sanshandao Gold Mine, which is the first and largest mine operating below sea level in China. An important discovery during a recent exploration in November 2015 was the presence of high-grade gold ore $(4 \mathrm{~g} / \mathrm{t})$. However, the Sanshandao Village, with a highly dense population and buildings and oil stocks, is directly above the mining stopes. Extensive damage to buildings has been found, and a strong dissatisfaction among the people has developed in recent years. Unfortunately, no measurements have been taken to monitor the ground deformation since mining began. Therefore, it is urgent to assess the ground deformation and identify the high-risk region. In this study, continuous monitoring every six months since 2009 provided huge amounts of measured data to assess the ground deformation. Additionally, the data can contribute to a deeper understanding of the process of ground deformation in metal mines. 


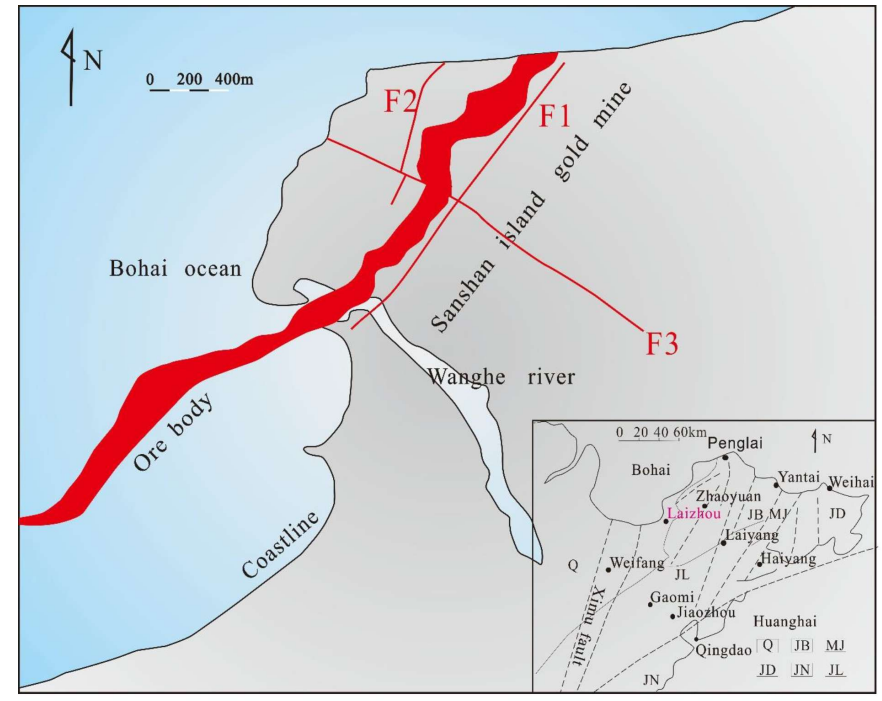

Fig. 1: Geological map of Sanshandao Gold Mine

\section{Geographical and regional geological setting}

Sanshandao Gold Mine is located in the coastal area of Laizhou (Shandong, China), which is surrounded by the ocean to the north and west. The ground altitude of the gold mine is approximately $1.2-4.5 \mathrm{~m}$. Sand overlays the bed rock up to a thickness of $40 \mathrm{~m}$.

As seen in Fig. 1, Sanshandao Gold Mine is located in the JiaoBei upheaval (JB), which is dominated by the North China Platform in the north, the YiMu fault zone in the west, the JiaoLai depression (JL) in the south, and MuPing in the east. In details, the gold mine belongs to the Sanshandao fracture, which is a secondary fracture of the YiMu fault zone. The outcrop of the Sanshandao fracture rises from Sanshandao in the northeast to Panjiawuzi in the southwest. There are three controlling faults in the mine area: F1, F2, and F3.

$\mathrm{F} 1$ is the ore-controlling fault and is approximately 2 $\mathrm{km}$ long in strike direction. The attitude is NE35 $5^{\circ}-40^{\circ} / \mathrm{SE} \angle 38^{\circ}$ with undulations in strike and dip. Altered rocks containing ore lie on the footwall of F1. The maximum horizontal thickness of the altered rocks is approximately $50 \mathrm{~m}$ and the depth exceeds $1000 \mathrm{~m}$. The main fracture plane lies on the hanging wall and contains a fault gouge approximately 4-45 cm thick.

F2 rises from the Bohai Ocean in the north to the kindergarten of Sanshandao Village. The average attitude of F2 is NE15/NW $\angle 60^{\circ}-80^{\circ}$. Additionally, F2 has a compressiveshear property, and its effect width is approximately $5-10 \mathrm{~m}$.

F3 lies near the exploration line of No. 1740-1760 and is the largest NNW fault with tensional-shear property in the mining area. The attitude is approximately NW305\%/NE $\angle 85^{\circ}$ or $\mathrm{NW} 305^{\circ} \perp$. Meanwhile, F1 was offset by $\mathrm{F} 3$ to approximately $20 \mathrm{~m}$ in the tectonic phase. F3 is wedge shaped in the depth direction and is only $1 \mathrm{~m}$ in width at $650 \mathrm{~m}$ depth. According to the investigation in the stope, the rock mass in the footwall is less damaged than that in the hanging wall due to mining.

\section{Geostress field}

Sanshandao Gold Mine is located in an active tectonic region with complex and high stress. The geostress was measured by using the stress relieving method which showed that the main stress is dominated by the horizontal stress and secondarily by gravity. In detail, the direction of the maximum horizontal stress is NNW, which is consistent with the Neocathaysian tectonic system. Additionally, the differential stress becomes larger with increasing depth. The regression equations of stress are as follows:

$$
\begin{aligned}
& 0 \text { to }-420 \mathrm{~m}(\mathrm{Miao} \text { et al., 2004): } \\
& \sigma_{-} \mathrm{hmax}=0.81+0.0449 \mathrm{H}(\mathrm{MPa}) \\
& \sigma_{-} \mathrm{hmin}=0.87+0.023 \mathrm{H}(\mathrm{MPa}) \\
& \sigma_{-} \mathrm{V}=0.28+0.0255 \mathrm{H}(\mathrm{MPa}) \\
& -510 \mathrm{~m} \text { to }-750 \mathrm{~m}(\mathrm{Cai} \text { et al., } 2013) \text { : } \\
& \sigma_{-} \text {hmax }=1.433+0.043 \mathrm{H}(\mathrm{MPa}) \\
& \sigma_{-} \text {hmin }=0.536+0.024 \mathrm{H}(\mathrm{MPa}) \\
& \sigma_{-} \mathrm{V}=0.838+0.027 \mathrm{H}(\mathrm{MPa})
\end{aligned}
$$

\section{Mining history}

Mining in this mine has been practiced for a period of at least 25 years. The ore body is carried out by the upward horizontal cut-and-fill method. In the process of backstopping, pillars are retained regularly to ensure the safe mining. The deepest mining level is $-825 \mathrm{~m}$ and interval thickness between two levels is approximately $40 \mathrm{~m}$. Thus, the mining direction is gradually trending to the north-east (Fig. 2) and the mining rate is approximately $8000 \mathrm{t} / \mathrm{d}$. The intensive mining disturbs of the rock mass and, therefore, may speed up the ground deformation.

\section{The layout of GPS points and GPS introduction}

GPS was used to investigate the ground deformation, and 315 monitoring points were established along the exploration lines in 2012. The monitoring network is composed of a reference net and a deformation net. Specifically, the reference net is away from mining induced deformation while the deformation net is located in region of concern. The stability of the reference net is the key to accurate monitoring result. During the 6-month monitoring process, the reference net worked well.

The receive equipment used is the Z-12-TYPE GPS receiver and antenna (Ashtech, USA) with $3 \mathrm{~mm}+0.5 \mathrm{ppm}$ nominal accuracy in horizontal displacement and $5 \mathrm{~mm}+1 \mathrm{ppm}$ in vertical displacement (Haijun et al., 2013). These precisions meet the requirements for measurements of ground deformation. The results show that the mean square error of the points was $\pm 1.9 \mathrm{~mm}$. The field monitoring intervals was 6 months. Therefore, the study of the Sanshandao Gold Mine has produced 3 years of data. 


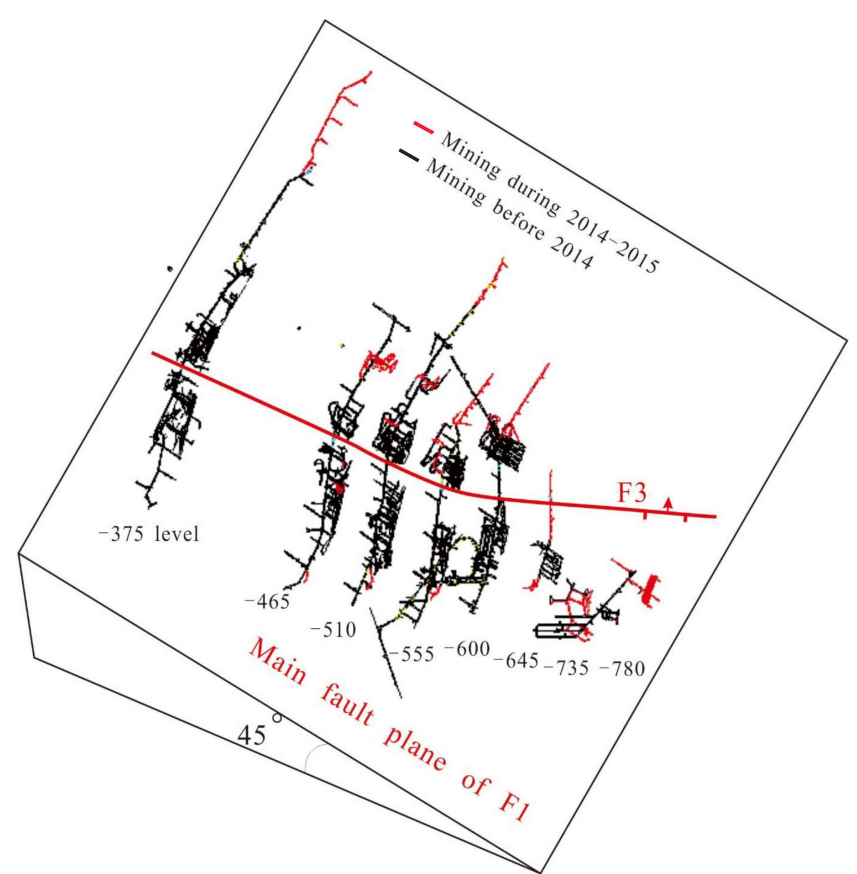

Fig. 2: Mining history of Sanshandao Gold Mine. Red tunnel represents the mining during 2014-2015, black tunnel represent the mining before 2014 .

\section{MONITORING RESULTS}

\section{Vertical and horizontal displacement}

The contour maps of vertical and horizontal displacement were obtained based on the monitoring data from 6 campaigns. These contour maps represent the deformation during the period of September 2012 to March 2015. However, the real displacement since mining began is much greater than the monitoring results. Contour maps of September 2012-March 2014 (Fig. 3a) and September 2012-March 2015 (Fig. 3b) were made to show the change in the vertical displacement. Additionally, the contour maps of September 2012- March 2014 (Fig. 3c) and 2012.9-2015.3 (Fig. 3d) were made to show the change in the horizontal displacement.

The region of ground deformation induced by mining in the Sanshandao Village has caused damage to building structure, pipes and bridges (Fig. 4). With continued mining, larger ground deformation is likely. As shown in Fig. $3 a$ and $3 b$, vertical displacement increased dramatically during the monitoring period. There are two main vertical displacement centers in the mining area due to the existence of an unexcavated ore body between the two centers. The maximum vertical displacement near monitoring point 3605 during half of the past one year and half of the past two years is $-75 \mathrm{~mm}$ and $-210.7 \mathrm{~mm}$, respectively. Additionally, the maximum vertical displacement nears monitoring point 0152 during half of the past one year and half the past two years is $-26 \mathrm{~mm}$ and $-124.5 \mathrm{~mm}$, respectively. However, the two centers are gradually becoming connected because of the mining of the underlying ore body. Meanwhile, the affected area of vertical displacement is quickly enlarging. The predominantly enlarged direction is in the southeast. Additionally, there are uplifted areas on the footwall of F1, which are not shown on the contour map. Horizontal displacement characteristics are shown in Fig. 3c and $3 d$. The maximum horizontal displacement near monitoring point 0152 has increased from $24.7 \mathrm{~mm}$ to $45 \mathrm{~mm}$. Another horizontal displacement center is located at monitoring point 4008 (from $16 \mathrm{~mm}$ to $115 \mathrm{~mm})$. In addition, the horizontal displacement direction is $31^{\circ} 27^{\prime}\left(60^{\circ} 55^{\prime}\right)$ at 0152 and $257^{\circ} 37^{\prime}\left(341^{\circ} 14^{\prime}\right)$ at 4008 in March 2014 (March 2015). The dramatic direction change (nearly $90^{\circ}$ ) at point 4008 shows the movement of the horizontal displacement centre towards the north.

\section{Tensile and compressive region}

To thoroughly understand the regularity of ground deformation, contour maps of tensile and compressive region were made. The tensile region is defined as the distance between any two monitoring points shrinks (negative value), while the compressive region defined as the distance between any two monitoring points grows (positive value). There are two contour maps: September 2012-March 2014 and September 2012-March 2015.

Along the dip direction of $\mathrm{F} 1$, the deformation regions were divided into a tensile region, compressive region and a tensile region (Fig. 5). The tensile region close to F1 is mainly distributed in the footwall of F1 and became smaller and smaller as the mining operation was carried out on the footwall of F1. The tensile region away from F1 is mainly distributed in the southeast and has become larger as the mining has progressed. The compressive region gradually enlarged along the F1. A small tensile region surrounded by the compressive region has disappeared due to the excavation of the underlying ore body. During the half and past two years, the compressive value at monitoring points 4405,2804 , and 0151 went from $-39.5 \mathrm{~mm}$, $-38.4 \mathrm{~mm}$, and $-44.6 \mathrm{~mm}$ to $-73.4 \mathrm{~mm},-111.1 \mathrm{~mm}$, and $-45 \mathrm{~mm}$, respectively. Similarly, the tensile value at points 4803 and 3606 went from $37 \mathrm{~mm}$ and $20.2 \mathrm{~mm}$ to $11.1 \mathrm{~mm}$ and $77.6 \mathrm{~mm}$, respectively.

\section{Inclined deformation and ground curvature}

Calculating the slope between the center point of vertical displacement and the surrounding points (Fig. 3a, 3b), it shows that there was no serious inclined deformation on the ground. Investigation of buildings also did not show corresponding damages caused by inclined deformation. The maximum slope around monitoring point 0152 trended in the NE direction, and the slope value cahnged from $10.78 \mathrm{~mm} / \mathrm{m}$ to $11.15 \mathrm{~mm} / \mathrm{m}$ between September2012 and March 2015. The slope around point 3605 showed some differences. Specifically, the slope in the SW and SE increased by $0.73 \mathrm{~mm} / \mathrm{m}$ and $0.18 \mathrm{~mm} / \mathrm{m}$, respectively, while the slope decreased in the $\mathrm{N}$ and $\mathrm{NW}$, and the maximum value was $0.59 \mathrm{~mm} / \mathrm{m}$ during the half and past two years. The curvature in the study area also showed a slight 

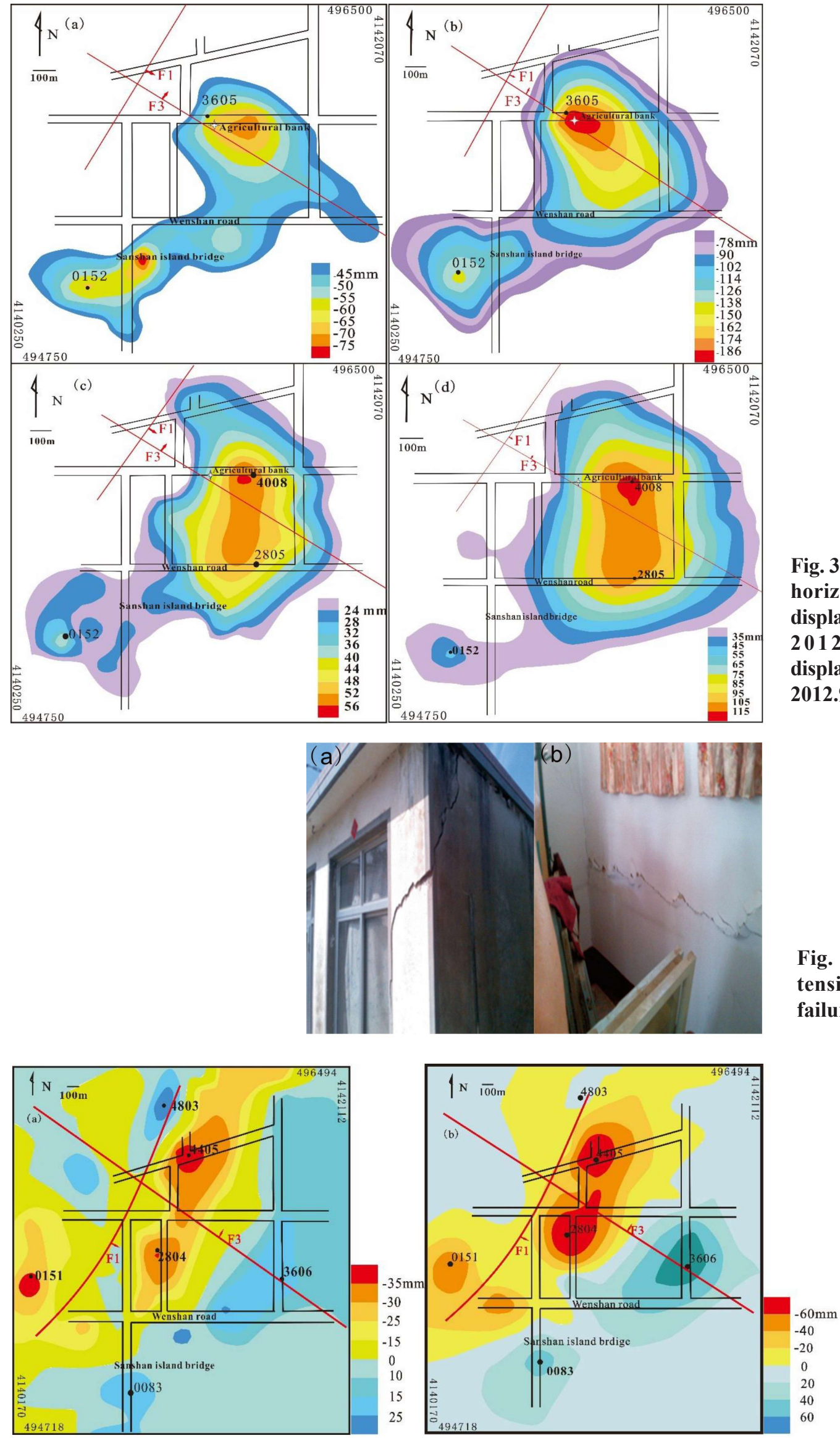

Fig. 3: Contour map of vertical and horizontal displacement. Vertical displacement: (a) 2012.9-2014.3. (b) 2012.9-2015.3. Horizontal displacement: (c) 2012.9-2014.3. (d) 2012.9-2015.3.

Fig. 4: Damage of buildings. (a) tension failure and (b) shearing failure
Fig. 5: Deformation region of stretch and compression. (a) 2012.92014.3 and (b) 2012.92015.3 

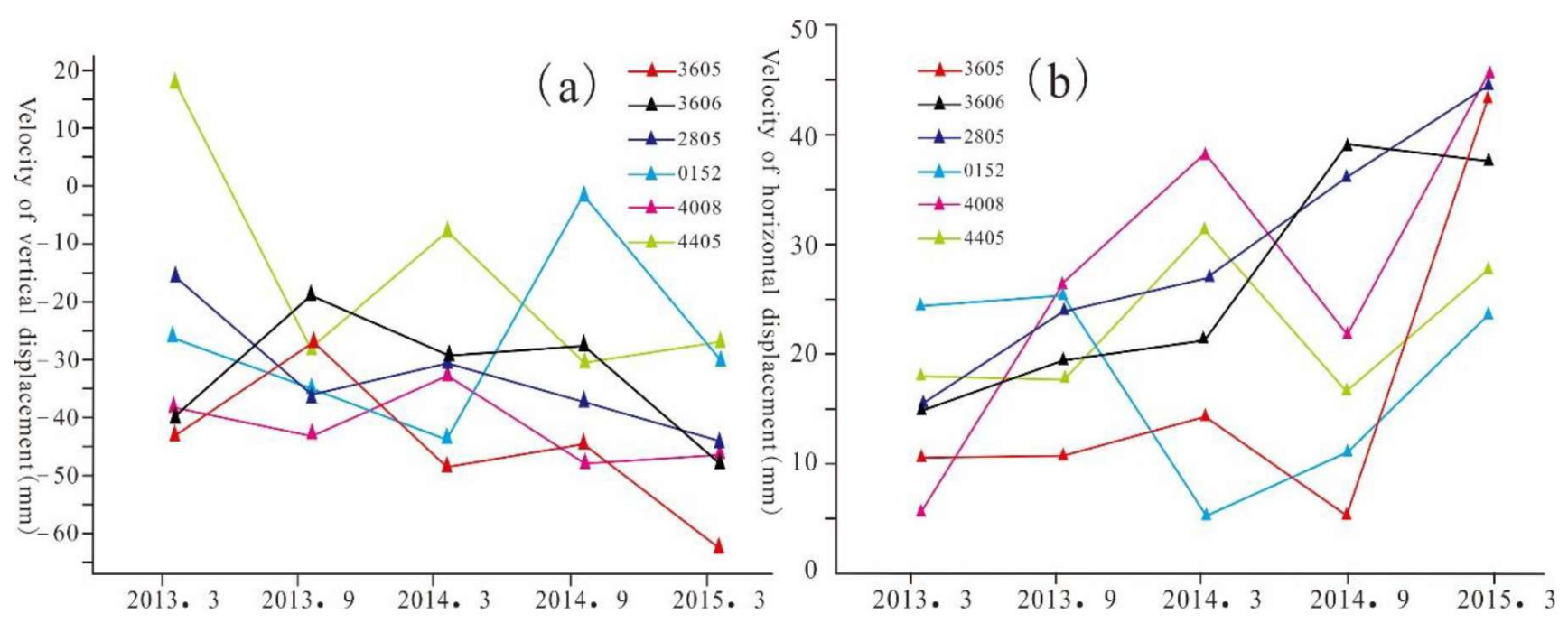

Fig. 6: The velocity of deformation. (a) velocity of vertical displacement and (b) velocity of horizontal displacement

change and even decreased over the study region. The development of curvature was dynamic as the mining went deeper and wider. In the seriously deformed area, the curvature value decreased by one order of magnitude. At the point 2805 , for example, the curvature decreased from $-0.12(10-3 / \mathrm{m})$ in September 2012 to $-0.05(10-3 / \mathrm{m})$ in March 2015.

\section{Velocity of ground deformation}

The ground deformation velocity is dynamic due to the different mining speed, and depth, the structure of the overlaying rock mass and tectonic stress. The velocities of vertical and horizontal displacement at points 3605, 3606, 2805, 0152, 4008 and 4405 are shown in Fig. 6. In general, the velocity of deformation tended to increase during the measurement periods. The vertical displacement in the northern area was larger than that in the southern area (Fig. 6a). Similarly, the velocity of horizontal displacement increased more quickly in March 2015, especially at points 3605 and 4008 (Fig. 6b). This pattern may be caused by the mining direction trending to the northeast along the footwall of F1.

\section{DISCUSSIONS}

\section{Controlling effect of F3 on ground deformation}

The main influence of faults is that ground deformation shows a localized discontinuity (Bell et al., 2005). Different types of faults can have different effects on the development of ground deformation because they have different dimensions, quality of fault plane, and mechanical causes.

F3 is a tensile-torsional strike fault with a dip angle close to $90^{\circ}$ and nearly perpendicular to F1. The ground deformation becomes more complex because F3 traverses the deformed region. The evolution of $\mathrm{F} 3$ can be divided into two stages: As the strength of rock mass along F3 is much lower than the surrounding rock mass, $\mathrm{F} 3$ presents the compressive-shearing motion along the fault plane due to the disruption by mining. As seen in Fig. 7e, the direction of slide on the two sides of F3 are opposing. The sliding of F3 is more obvious in the adjacent region of $\mathrm{F} 1$. Then, as the mining stopes extend to the northeast, the rock mass tends to move to the north-east as shown in Fig. 7e. The direction of vectors at points 4405, 4805 and 4008 changes at an obtuse angle. The rock mass tends to be pulled apart along the normal direction of F3. Therefore, F3 presents a tensile-shearing model leading to a discontinuous and more serious deformation along the strike of F3 (Nie et al., 2013).

The discontinuous deformation can also be demonstrated by Fig. 5, which shows that $\mathrm{F} 3$ divides the compressive region into two parts. The tensile fault can be regarded as the stress release area, especially in the shallow part (Brune et al., 1999). Tectonic stress has little effect on these areas. As a consequence, a relatively small value of compression occurs when comparing the two sides of F3. Additionally, the width of F3 is approximately $20 \mathrm{~m}$, and the rock mass in this region is more cracked and has the greater probability of sliding. This condition results in a larger value of vertical and horizontal displacement along the strike direction of F3 than in the surrounding area (Fig. 3).

Another controlling effect of F3 is the consolidation of the sand layer. In details, F3 is becoming a new flow path for surface water after sliding (Jie et al., 2015). When the water reserved in the sand flows through the fault into the underground, the pore water pressure in the sand layer decreases quickly and the effective stress increases by a corresponding value. This process ultimately causes the consolidation of the sand layer. Finally, the additional deformation is added to the mining induced deformation. The discontinuous deformation along the two sides of $\mathrm{F} 3$ may become more serious as the mining continues to the northeast. Additionally, the damage to buildings along F3 should be monitored more carefully and frequently. 


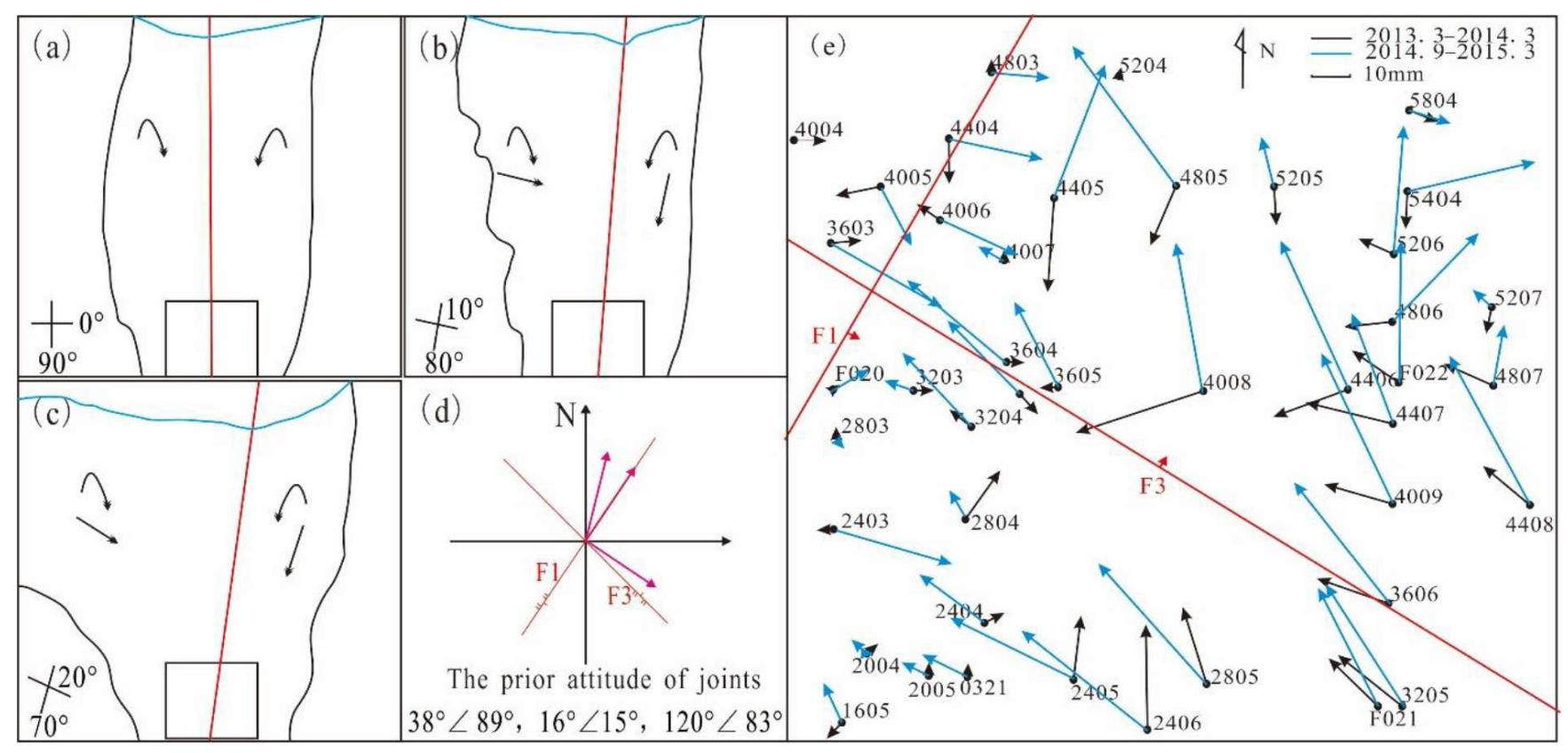

Fig. 7: (a), (b), (c), (d) the relationship between joints and rock mass movement. (e) Horizontal displacement vector

\section{Relationship between joints and ground deformation}

The prior direction of rock mass movement is close to the stopes and the direction of transmission of rock movement and the initial center of ground deformation are strongly influenced by the attitude of joints (Fig. 7a, 7b, and 7c). Joints with steep dip angle mainly cause the vertical and rotary displacement of rock mass and the center of deformation correspondingly tends to be located directly above the stope. In addition, joints with steep dip angles cause more serious subsidence but a relatively small range of deformation. In contrast, joints with shallow dip angles generally cause the sliding of rock mass along the joint plane and the deviation of the deformation center. The relative position between the stope and the direction of the dip also influences the ground deformation. When the dip points to the stope, the rock mass can easily slide along the joint plane. Otherwise, the rock mass tends to rotate around the joint plane. This difference can cause the asymmetric ground deformation (Vyazmensky et al., 2010).

According to the statistical analysis of joints (904 strips) measured at levels from $-150 \mathrm{~m}$ to $-645 \mathrm{~m}$, three prior attitudes are determined: $38 \circ 89^{\circ}, 16^{\circ} \angle 15^{\circ}, 120^{\circ} \angle 83^{\circ}$. Fig. $7 d$ depicts the relationships of attitudes between F1, F3 and three prior joints. The dips of the first and third joints are nearly consistent with the strike of F1 and F3. In fact, joints with dip angle between F1 and F3 in the NW direction are much denser than in other areas (Hongjun, 1993). Considering that the stope lies on the footwall of F1 and combining Fig.3a and b, the high gradient of contour value in the region close to F1 indicates that the vertical displacement is much larger as the rock is divided by the two joints with steep dip angles. The second prior joint mainly causes horizontal displacement and may intensify the horizontal displacement in the north-south direction. Due to the limitation of the measured data, the accurate relationship between joints and ground deformation in the Sanshandao Gold Mine requires more investigation.

\section{Effect of high tectonic stress}

Ground deformation is closely related to the magnitude and orientation of the maximum principal stress. On the one hand, horizontal displacement induced by gravity and the unloading of the rock mass has a larger impact region. On the other hand, if the orientation of maximum principal stress and the attitude of joints are consistent, the vertical displacement will increase on the hanging wall of the ore-controlling fault. The unloading of rock mass in the tunnel can be regarded as the decrease of confining pressure. According to the MohrCoulomb model (Georg Mandl 2000), the normal stress on the joint plane will decrease as the confining pressure decreases and, therefore, will make the rock mass easier to slide along the joint plane. A special phenomenon in high tectonic stress areas is that an uplifted region may occur along the ore-controlling fault plane due to the intensive compression of tectonic stress. Since the mining operation is carried out on the footwall of the ore-controlling fault, the overburden can be thought of as a "beam" (Fig. 8). Under this condition, high tectonic stress bends the "beam" and the rock mass is uplifted.

In the Sanshandao Gold Mine, the dominant tectonic stress is horizontal stress. The orientation of the maximum principal stress and the intermediate principal stress is in the NWW and NS direction, respectively. The ground deformation region presents a striped deformation, as the compression by the maximum principle stress is in the NWW direction (Fig. 5). 


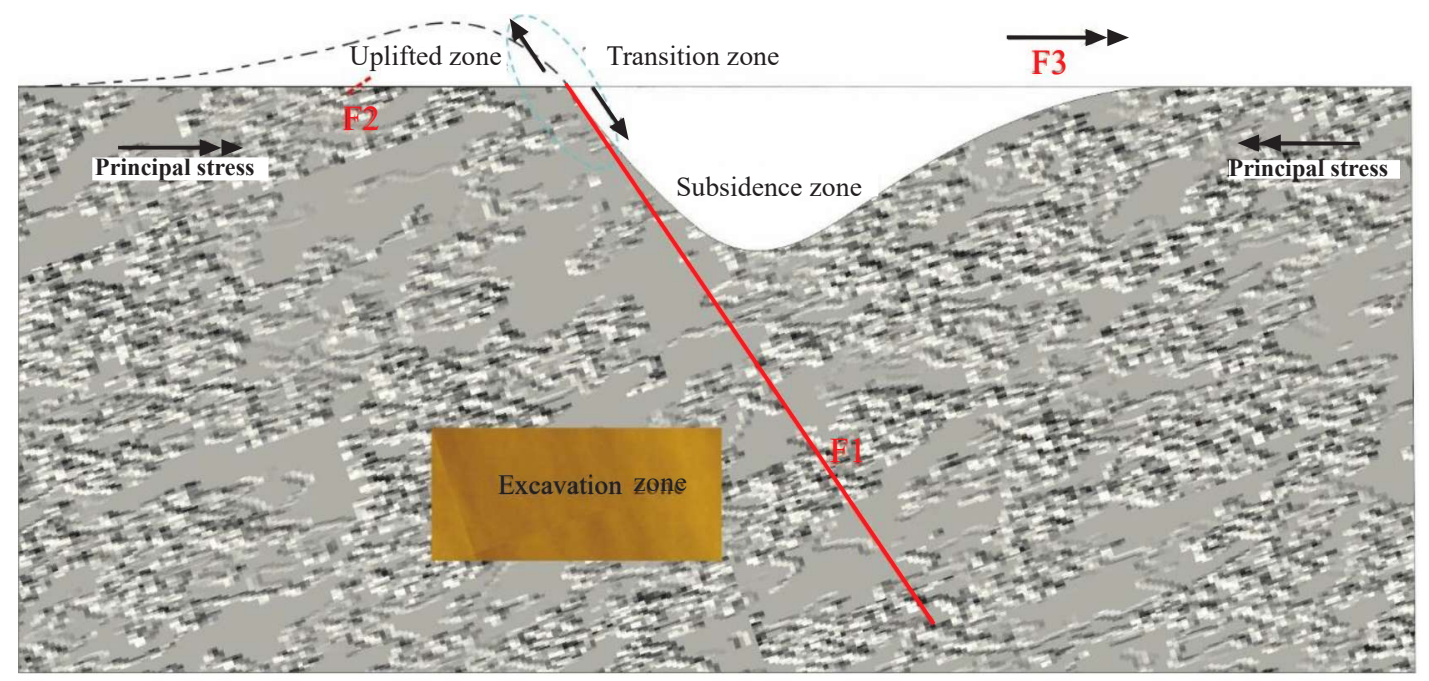

Fig. 8: The influence of tectonic stress: uplifted zone, transition zone and subsidence zone

Fig. 7e describes the vector of horizontal displacement during the periods March 2013-March 2014 and September 2014-March 2015. Rock mass near F1 moves slightly more towards the center than that far away from F1. The prior direction of motion is NWW and NS, which is consistent with the orientation of principal stresses and can be reflected in Fig. 3c and $3 \mathrm{~d}$, where the contour is convex in the NS and NWW direction. Additionally, a slightly uplifted region between F1 and F2 was found during the monitoring phase, and the maximum value is $8 \mathrm{~mm}$ during the previous two and a half years. The transition zone (Fig. 8) between the uplifted region and the subsidence region may undergo an intensive shearing action, which may cause a sudden failure of rock mass in the future.

\section{CONCLUSIONS}

Though the cut-and-fill method is employed in the Sanshandao Gold Mine, serious ground deformation has still occurred. Unfortunately, Sanshandao Village is right above the exploitation range, and many buildings have been damaged because of the differential movements and flexing of the ground. Therefore, it is urgent to monitor the ground deformation to protect life and property.

During the process of mining, the value and range of ground deformation constantly increased. The deformation characteristics in the study area are complex due to the dense joints, high tectonic stress and several intersecting faults. The two evolution stages of F3 are important for the deformation; the two evolution stages are compressive-shearing motion along the fault plane and then tensile-shearing motion. Discontinuous ground deformation along the strike of F3 is especially obvious and will be more serious when the mining area extends in the northeast direction. Specifically, the fault step may occur along the strike of F3, especially in the region close to the edge of the working mine. Additionally, the attitudes of prior joints could contribute to the displacements of rock mass and the high tectonic stress gives the ground deformation a striped formation.

Different characteristics of ground deformation have been recognized and can affect different building structures in different ways. The main reason for the damages to buildings is the compressive and tensile deformation, where the latter is generally more serious as far as structural failure is concerned, while damages to buildings due to slope and curvature are relatively slight because the values are relatively small. The seriously damaged buildings are located between Wenshan Road and Agricultural Bank. Tensile-shearing action through the wall may mainly occurs along the strike of F3. Special attention should be paid to the northern area of F3 in the future.

\section{ACKNOWLEDGMENTS}

The research was supported by the National Natural Science Foundation of China (Grant Nos. 41372323). Grateful appreciation is expressed for the support.

\section{REFERENCES}

Akçýn, H., Degucci, T., and Kutoglu, S.H., 2006, Monitoring mining induced subsidence using GPS and InSAR. TS 48-engineering surveys for construction works II, XXIII FIG congress, October 8-13. Munich, Germany.

Bell, F.G., Donnelly, L.J., Genske, D.D., and Ojeda, J., 2005, Unusual cases of mining subsidence from Great Britain. Germany and Colombia, Environ Geol., vol. 47, pp. 620-631.

Brune, J.N. and Anooshehpoor, A., 1999, Dynamic geometrical effects on strong ground motion in a normal fault model. J Geophys Res, vol. 104(B1), pp. 809-815.

Cai, M., Ji, D. and Guo, Q., 2013, Study of rockburst prediction based on in-situ stress measurement and theory of energy accumulation caused by mining disturbance. Chinese Journal of Rock Mechanics and Engineering, vol. 32(10), 
pp.1973-1980 (in Chinese).

Can, E., Mekik, C., Kuscu, S., and Akçýn, H., 2013, Monitoring deformations on engineering structures in Kozlu Hard Coal Basin. Nat Hazards, vol. 65, pp. 2311-2330.

Donnelly, L.J., 2006, A review of coal mining induced fault reactivation in Great Britain. Engn Geol Hydrogeol, vol. 39 , pp.5-50.

Georg, M., 2000, Faulting in brittle rocks: an introduction to the mechanics of tectonic faults. Springer-Verlag Berlin Heidelberg $\mathrm{GmbH}, 113 \mathrm{p}$.

Guo, Q., Qiao, S., and Liu, B., 2011, The Movement and Deformation of Soil and Rock Mass Resulted from Mining Activity. Journal of Mining \& Safety Engineering, vol. 28(1), pp. 109-114 (in Chinese).

Loupasakis, C., Angelitsa, V., Rozos, D., and Spanou, N., 2014, Mining geohazards-land subsidence caused by the dewatering of opencast coal mines: The case study of the Amyntaio coal mine, Florina, Greece. Nat Hazards, vol. 70, pp. 675-691.

Ma, F., Zhao, H, Renmao, Y., and Guo, J., 2015, Ground movement resulting from underground backfill mining in a nickel mine (Gansu Province, China); Nat Hazards, vol. 77(3), pp. 1-16.
Miao, S., Wan, L., Lai, X., and Wang, S., 2004, Relation analysis between in-situ stress field and geological tectonism in sanshandao gold mine. Chinese Journal of Rock Mechanics \& Engineering, vol. 23(23), pp. 3996-3999 (in Chinese).

Muntean, A., Mocanu, V., and Ambrosius, B., 2016, A GPS study of land subsidence in the Petrosani (Romania) coal mining area. Nat Hazards, vol. 80, pp. 797-810.

Nie, L., Zhang, M., and Jian, H., 2013, Analysis of surface subsidence mechanism and regularity under the influence of seism and fault. Nat Hazards, vol. 66, pp. 773-780.

Sheorey, P.R., Loui, J.P., Singh, K.B., and Singh, S.K., 2000, Ground subsidence observations and a modified influence function method for complete subsidence prediction. Int J Rock Mech Min Sci, vol. 37, pp. 801-818.

Stecchi, F., Mancini, F., Ceppi, C., and Gabbianelli, G., 2012, Vulnerability to ground deformation phenomena in the city of Tuzla (BiH): a GIS and multicriteria approach. Nat Hazards, vol. 64, pp. pp. 2153-2165.

Vyazmensky, A., Elmo, D., and Stead, D., 2010, Role of Rock Mass Fabric and Faulting in the Development of Block Caving Induced Surface Subsidence. Rock Mech Rock Eng, vol. 43, pp. 533-556. 